\title{
MEDD|JSKA PISMENOST
}

\section{Opšta situacija}

$\mathrm{U}$ medijskim industrijama $\mathrm{u}$ toku je proces velikih promena. Njih izazivaju tehnološke i poslovne inovacije koje se uvode u poslednje dve decenije i čiji uticaj svake godine raste.

\section{Tehnološke inovacije}

Najznačajnija tehnološka inovacija je pojava kompjutera. No, kao tehnologija, kompjuter se ne može smatrati samo jednim od kanala distribucije poruka; on je inovacija koja u svim postojećim masovnim medijima postaje deo distribucije poruka. Kompjuter nije samo kanal koji omogućava pristup porukama na internetu. On omogućava i pristup porukama koje su se ranije mogle naći samo u određenim dnevnim listovima, časopisima, knjigama, snimljenim zapisima i filmovima. Kompjuter često ima oblik čipa koji se ugrađuje u televizor ili DVD plejer i omogućava programiranje gledanja omiljenih emisija, odstranjivanje potencijalno štetnih poruka (V-čip), gledanje emisija s prevodom i menjanje veličine i rezolucije ekrana. Kompjuter je čip koji se ugrađuje u iPod i omogućava zajedničko posedovanje muzike i njenu dostupnost u svim konfiguracijama i bilo kojim redosledom. Kompjuterski čipovi omogućuju svima da stvaraju poruke (tekstove, fotografije, pokretne slike i zvuke), da ih montiraju i redovno distribuiraju velikom broju anonimnih osoba. $\mathrm{Na}$ taj način ta tehnološka inovacija znatno smanjuje prepreke da pojedinci delaju kao mas-medijska organizacija.

Kompjuterska tehnologija dovela je do još jedne inovacije - digitalizacije poruka. Svaka poruka može se izraziti kao kompjuterski kod u jednostavnom binarnom formatu. Kada se kodira, poruka se može lako prenositi svim medijima. Na taj način, prepreke koje tradicionalno razdvajaju različite medije u posebne

kanale distribucije nestaju.

\section{Poslovne inovacije}

Nekada je nov medij, kada se u fazi prodora razvio i došao do faze vrhunca, otkrivanjem novih potreba koje on nije 


\section{DŽEJMS POTER}

zadovoljavao, primoravao ostale medije da se prilagođavaju. To znači da se stariji mediji prilagođavaju tako što svoje poslovanje čine drugačijim od novijeg medija. Ali sve veća prisutnost kompjutera može promeniti takvo stanje stvari. Čini se da kompjuter primorava ostale postojeće medije na međusobno približavanje i doprinosi ukidanju razlika među njima. Ukratko, kompjuter u stvari jača usmerenost na poruku a ne na kanal kojim se ona prenosi; to jest, marketinška posebnost ogleda se u načinu na koji poruka privlači publiku a ne u mediju koji se koristi za njeno prenošenje. Potom, kada urednik masovnih medija stvori jasnu poruku koja odgovara određenoj publici, on koristi sve medije kao sredstva da dopre do što većeg broja pripadnika te publike.

\section{Opšte tendencije u pogledu zapošljavanja}

Rast i razvoj medijskih industrija pokreće sledeća pitanja: koliko su velike pojedine mas-medijske industrije u pogledu broja zaposlenih i kakve su karakteritike ljudi koji rade u masovnim medijima?

\section{Ukupni obim radne snage}

Situacija u pogledu radne snage u medijima je solidna i ukupan broj zaposlenih u medijskim industrijama raste za oko tri odsto godišnje. Može, međutim, delovati iznenađujuće podatak da je broj ljudi koji rade u tim industrijama prilično mali kada se imaju u vidu velika prisutnost tih industrija u javnosti i njihov jak uticaj.

Dnevni listovi godinama su najveći poslodavci među masovnim medijima, ali broj zaposlenih u njima polako opada dok u drugim industrijama broj zaposlenih raste, naročito kada je reč o proizvodnji softvera i kablovskoj televiziji. Rast broja zaposlenih i broja kompanija u oblasti kablovske televizije ukazuje na verovatnoću da će taj medij još prilično dugo ostati u fazi vrhunca; nagoveštaja opadanja još nema.

Današnja publika ima brojne mogućnosti za gledanje televizijskih emisija. Ako propusti njeno emitovanje, može da je snimi, da programira njeno snimanje, da je kupi na programu iTunes za 1,99 dolara ili da je dobije besplatno na veb televiziji koja prenosi popularne emisije, uz pridodate reklame. Urednike te televizije ne brine parcijalizacija njihove publike; oni smatraju da veb televizija uvećava broj gledalaca i obezbeđuje širu gledanost konkretne emisije.

Kompanija Apple je oktobra 2001. pustila na tržište iPod i u narednih pet godina prodala je šezdeset miliona primeraka; analize pokazuju da je iPod kod studenata koledža popularniji od piva. 


\section{DŽEJMS POTER}

Kada je Apple uveo iTunes ljudi su umesto albuma počeli da kupuju pojedinačne pesme. Zahvaljujući iPodu mogu se stvarati sopstveni albumi i nizovi melodija. Prethodnik iPoda bio je vokmen kompanije Sony koji se na tržištu pojavio 1979. Ali na iPod može da stane mnogo više muzike (nečija čitava muzička zbirka) i on omogućava slušanje bilo koje pesme po želji. Od 2004. moguće je snimiti sopstvenu muziku i u digitalizovanom obliku proslediti je drugima. Današnja peta generacija iPoda prima i video snimke.

Warner Brothers je krajem 2006. posredstvom kompanije AOL pustio na tržište više od sto starih televizijskih serija i time obezbedio još jedan izvor prihoda. To je pokušaj, nazvan In2TV, da se iskoriste mogućnosti koje pruža brzo rastuće tržište oglašavanja na Internetu.

Čak i takozvani alternativni dnevni listovi međusobno se kupuju i postaju konglomerati. U jesen 2005. New Times, koji je već bio vlasnik jedanaest nedeljnih listova, kupio je Village Voice Media, Inc., vlasnika Village Voice, OC Weekly i LA Weekly. Ti dnevni listovi zajedno ostvaruju ukupan godišnji prihod od sto osamdeset miliona dolara.

Televizija je danas manja (mobilni telefoni), veća (televizori s velikim ekranom u dnevnim sobama) i u većoj meri je prenosiva (televizori u automobilima i MP3 plejeri). Televizijski signal (čak i visoke rezolucije) raspoloživ je gotovo svuda i u svako doba posredstvom TV kanala HDNet Marka Kjubana koji program emituje preko kablovske televizije i satelita. Podešavanjem komandi na video rikorderu možemo da gledamo šta god želimo i kad god želimo. No, veće mogućnosti izbora dovode do toga da ljudi sužavaju svoj izbor i manje su voljni da u njega uključuju nove programe.

Kompanija Yahoo, Inc. počela je agresivno da ubeđuje holivudske producente da stvaraju emisije koje će biti prikazivane isključivo na njenoj mreži veb-sajtova. Želela je da sa preuzimanja filmskih trejlera i TV klipova pređe na prikazivanje originalnih neskraćenih emisija. HBO je počeo tako što je prikazivao holivudske filmove tek kada je od prestanka njihovog prikazivanja u bioskopima proteklo više meseci; već 2000. postao je veliki kupac novih filmova.

Izdavači romana danas oglašavaju romane koristeći video trejlere na veb-sajtovima. Neki od njih su dramatizacije uz učešće glumaca i liče na filmske trejlere.

Kompanija Verizon Wireless počela je da nudi video klipove u okviru svojih usluga mobilne telefonije. Klipove preuzima od YouTube (čiji je vlasnik Google) i Revver, Inc. 


\section{DŽEJMS POTER}

Obe te firme koje nude video usluge nude i video klipove na Internetu. Revver prikazuje reklame posle svakog klipa i deli zaradu sa autorima.

\section{Knjige}

Obim industrije knjiga. Broj izdavača knjiga se sa oko dvadeset hiljada krajem devedesetih godina proteklog veka povećao na više od sedamdeset osam hiljada danas. Gotovo svi ti izdavači su mali - štampaju samo jedan do četiri naslova godišnje.

Ova industrija sada proizvodi oko sto sedamdeset pet hiljada naslova godišnje. Broj naslova se svake godine povećavao, od oko jedanaest hiljada u 1950. na šezdeset osam hiljada u 1996, ali je do velikog povećanja došlo u poslednjih deset godina - u 2006. objavljeno je sto sedamdeset pet hiljada naslova.

U SAD ima oko dvadeset hiljada knjižara, ali se njihov broj smanjuje jer male nezavisne knjižare ne mogu da izdrže konkurenciju velikih lanaca (kao što su Barnes \& Noble, Borders i Books-A-Million) i prodavaca knjiga na internetu, kao što je Amazon.com. Na internet knjižare odlazi oko osam odsto ukupne godišnje prodaje knjiga. Ima i sto sedamdeset pet klubova čitalaca.

Oblasti izdavanja i prodaje knjiga i s njima povezane oblasti obuhvataju oko dve stotine dvadeset hiljada radnih mesta.

Prihodi. Od prodaje oko dve milijarde knjiga svake godine današnja industrija knjiga ostvaruje godišnje prihode od oko trideset milijardi dolara.

Tržište je segmentirano i samo oko dvadeset četiri odsto prodaje odnosi se na opšte knjige (knjige s tvrdim i mekim povezom namenjene opštoj čitalačkoj publici, kao što su knjige o hobijima, putovanjima, kako da sami sebi pomognete, kuvanju i beletristika). Osamnaest odsto prodaje odnosi se na priručnike (za određena zanimanja), četrnaest odsto na udžbenike za osnovnu i srednju školu i četrnaest odsto na udžbenike za koledž. Oko šest odsto odnosi se na knjige mekog poveza za masovno tržište.

Amerikanci na knjige troše u proseku oko sto dolara godišnje. Ali broj ljudi koji kupuju knjige relativno je mali.

Većina knjiga prodaje se preko knjižara. Najveći deo te prodaje ostvaruje se u veoma velikim lancima kao što su Waldenbooks

ili Barnes \& Noble. 


\section{DŽEJMS POTER}

Troškovi. Brojni su elementi koji utiču na troškove u izdavaštvu. Uzmimo kao primer jednu knjigu u tvrdom povezu koja se u knjižarama prodaje za 19,95 dolara. Od te cene knjižari ide četrdeset osam odsto za sopstvene troškove i profit, a preostalih 10,37 dolara ide izdavaču. Fizička proizvodnja knjige (urednički poslovi, prelom, likovno rešenje korica, hartija, štampanje, povezivanje itd.) košta izdavača oko dva dolara. Narednih tri dolara odnose se na režijske troškove u koje spadaju troškovi recenzije, osoblja, marketinga itd. Autor dobija oko dva dolara na ime autorskih prava. Preostalih 3,37 dolara su profit, ukoliko knjižare ne vrate neprodate primerke knjige - što je uobičajena praksa - čime se taj profit umanjuje.

Rizici. Tek svaka peta knjiga postiže uspeh, to jest nakon podmirenja svih troškova donosi profit izdavaču. U stvari, funkcionisanje ove industrije i upuštanje u objavljivanje raznovrsnih ,rizičnih” knjiga i novih autora, omogućuje mali broj uspešnih knjiga. Od šezdeset osam hiljada novih naslova koji se godišnje objavljuju, znatno manje od jedan odsto dospeva na neki spisak bestselera. Na primer, na takvim spiskovima se u 1997. našlo samo osamdeset osam beletrističkih naslova; osamdeset pet odsto tih knjiga napisali su autori koji su već bili na spiskovima te vrste. Rizici uslovljavaju da izdavači agresivno primenjuju marketinški pristup; to jest, opredeljuju se za objavljivanje knjiga za koje smatraju da ih čitalačka publika želi, umesto za knjige za koje oni smatraju da su sa umetničkog ili obrazovnog stanovišta najpoželjnije. Izdavači smatraju da čitalačka publika traži knjige o skandalima, slavnim osobama, kuvanju, samopomoći i dijeti; otuda se godišnje objavljuje tako veliki broj knjiga na te teme.

Koncentracija. Od dve hiljade sedam stotina izdavača knjiga, njih hiljadu dve stotine objavljuje najviše pet knjiga godišnje. Osam najvećih izdavača obično ostvaruju polovinu ukupnih prihoda. Oblast izdavaštva je segmentirana, što znači da su različite grupe izdavača specijalizovane za određene segmente tržišta. Ali i u okviru tih segmenata postoji tendencija ka koncentraciji. Na primer, kada je reč o knjigama s mekim povezom namenjenim masovnom tržištu, sedam najvećih izdavača ostvaruje više od osamdeset odsto celokupne prodaje. Kada je reč o bestselerima, obično se osamdeset pet odsto naslova s tvrdim i osamdeset tri odsto $s$ mekim povezom vezuje za šest velikih izdavača (Random, Simon \& Schuster, Penguin Putnam, Bantam Doubleday and Dell, HarperCollins, Time Warner). Ako se tome dodaju naslovi šest drugih manjih izdavača dolazi se do devedeset osam odsto svih bestselera.

Najnovija prilagođavanja. Izdavači sve više žele knjige manjeg obima jer je dužina pažnje koju čitalačka publika posvećuje 


\section{DŽEJMS POTER}

knjizi smanjena dugogodišnjim gledanjem televizije. Nekada su knjige obično sadržale sedamdeset pet hiljada reči ili oko tri stotine štampanih strana, ali današnji bestseleri su znatno kraći. Na primer, knjiga Ko je maznuo moj sir? (Who Moved My Cheese?), čiji su autori Ken Blančard i Spenser Džonson, imala je samo sedamdeset sedam strana.

\section{Na način objavljivanja i distribucije knjiga utiče $i$ internet.}

Danas, kada izdavač objavi novu knjigu, on je često ponudi u štampanom i elektronskom obliku. Takozvane elektronske knjige čitaju se posredstvom ,čitača”, aparata koji se drže u ruci i rade na baterije. Tekst se pojavljuje na ekranu a ne na štampanim stranicama. Elektronske knjige su se pojavile 1998. i u prvoj godini prodato ih je manje od deset hiljada primeraka. Već naredne godine više od hiljadu pet stotina različitih naslova bilo je

ponuđeno u tom obliku.

Knjižare su sve prisutnije na internetu. Amazon.com počeo je da funkcioniše jula 1995. Naredne godine ostvario je prodaju od petnaest miliona dolara; no, njegovi troškovi u toj godini iznosili su dvadeset miliona dolara. Barnes \& Noble se uključio u internet prodaju da bi svojim knjižarama „od cigle i maltera” dodao još jedan izvor prihoda.

Samostalno izdavanje knjiga. Svako može da uz relativno male troškove objavi sopstvenu kompjuterski uređenu knjigu i da je ponudi na internetu. Knjige koje se u početku ili isključivo objavljuju na internetu nazivamo elektronskim knjigama. Neke od njih nikada ne dožive papirno izdanje već ih izdavači prodaju u elektronskom obliku koji kupac preuzima sa interneta; to su takozvane preuzete knjige.

\section{Novine}

Obim industrije novina. Postoji oko devet hiljada osam stotina različitih novina - petnaest odsto su dnevni listovi, sedamdeset sedam odsto nedeljnici, a ostatak su polunedeljnici. Ukupan tiraž svih dnevnih listova iznosi pedeset šest miliona primeraka, dok nedeljnici i polunedeljnici zajedno imaju tiraž od sedamdeset miliona primeraka. USA Today se objavljuje u 2,1

milion primeraka.

Prihodi. Aktuelni prihodi novina iznose oko 47,5 milijardi dolara godišnje. Izvori tih prihoda su brojni i u njih spadaju oglašavanje, pretplata s kućnom dostavom, prodaja na kioscima, pretplata na internetu, štampanje prema ugovoru, autorska prava za sadržaj, distribucija umetaka, usluge grafičkog dizajna i prodaja spiskova adresa. 


\section{DŽEJMS POTER}

Udeo listova u prihodima od oglašavanja opao je sa dvadeset sedam odsto u osamdesetim godinama proteklog veka na oko osamnaest odsto danas.

Troškovi. Najvećitroškovilistova odnose senazaposlene ičine oko šezdeset odsto ukupnih troškova. Ti troškovi rastu svake godine, ali po umerenoj stopi od tri do četiri odsto.

Profit. Prosečna profitna marža izdavača novina je oko sedamnaest odsto i veća je za više od tri puta od prosečne profitne marže kompanija na spisku pet stotina najvećih kompanija časopisa Fortune. Lejsi i Blančard (2003) izvršili su analizu sedamdeset sedam dnevnih listova i ustanovili da dnevni listovi u državnom vlasništvu ostvaruju veće profitne marže od onih u privatnom vlasništvu. To se pripisuje manjem broju zaposlenih. Takođe, početne plate u dnevnim listovima $u$ državnom vlasništvu su veće.

Listovi u vlasništvu lanaca kompanija još su unosniji. Njihov prvenstveni cilj je ostvarivanje što većeg profita za matičnu kompaniju. Stoga su veoma motivisani za povećanje prihoda (uklanjanjem konkurencije) i smanjenje troškova (primenom ekonomije obima). I listovi koji ne pripadaju lancima kompanija nesumnjivo imaju sličnu motivaciju kada je reč o profitu, ali lanci imaju veću ekonomsku snagu. Oni koriste sledeće metode: (a) troškovi prvog primerka amortizuju se većim tiražima te se tako ostvaruju niži troškovi po jedinici proizvoda (troškovi prvog primerka su fiksni i oni su kod listova s malim tiražom veoma visoki - dostižu čak četrdeset odsto ukupnih prihoda - te veća prodaja snižava te troškove); (b) troškovi reprodukcije opadaju s povećanjem tiraža (dodatne strane ne koštaju toliko koliko prvih nekoliko strana); i (c) distribucija je efikasnija kada je prostorna koncentracija čitalaca veća, a to ne ide u korist isporučiocima većeg broja različitih listova.

Lokalnost. Gotovo svih hiljadu pet stotina dnevnih listova u SAD lokalno su orijentisani; to jest, namenjeni su čitaocima u gradu u kome oni žive i u neposrednoj okolini. Samo mali broj listova (kao što su USA Today, Wall Street Journal i Christian Science Monitor) prodaju se zaista širom zemlje i bave se temama od značaja za celu zemlju. Po lokalnosti, listova Amerika je jedinstvena među industrijski razvijenim zemljama u svetu. U većini drugih zemalja listovi se izdaju u nekolicini velikih gradova i prodaju se širom zemlje. Na primer, u Tokiju živi jedanaest odsto japanskog stanovništva, ali dnevni listovi koji izlaze u tom gradu čine sedamdeset odsto tiraža listova u čitavom Japanu. Četrnaest odsto stanovništva Engleske živi u Londonu a na londonske dnevne listove dolazi sedamdeset odsto ukupnog tiraža. U Americi, gradovi Njujork i Vašington zajedno čine sedam 


\section{DŽEJMS POTER}

odsto američkog stanovništva, ali njihovi listovi čine samo deset odsto ukupnog tiraža dnevnih listova u SAD. Očigledno je da se listovi u toj zemlji izdaju na lokalnom nivou.

Koncentracija. Iako se listovi izdaju na lokalnom nivou, njihova vlasnička koncentracija je sve veća, to jest manji broj ljudi poseduje sve veći broj listova. Tendencija ka većoj koncentraciji iskazuje se na dva načina: u smanjenju konkurencije među listovima i u njihovom sve prisutnijem prelasku u vlasništvo lanaca kompanija.

Konkurencija među listovima u velikoj meri je smanjena. Na primer, broj gradova u kojima postoje konkurentski dnevni listovi sve je manji. Više od šezdeset odsto američkih gradova je 1900, imalo konkurentske listove, a danas ih ima manje od jedan odsto. Za opadanje konkurencije listova navode se dva razloga. Prvo, političke stranke više ne pružaju podršku listovima kao nekada, čime je došlo do smanjenja partnerstva između američke štampe i pojedinih stranaka. Drugo, oglašivači traže velike tiraže i raznoliku čitalačku publiku. Posledica toga je da veći list u gradu s dva takva lista dobija oglase i nastavlja da raste. List s manjim tiražom gubi oglase i na kraju prestaje da izlazi.

Veličina i broj lanaca kompanija u stalnom su porastu. U 1909. bilo je samo trinaest lanaca koji su posedovali samo dva odsto listova. Do 1970. lanci su lagano napredovali i tada je većina dnevnih listova bila u vlasništvu ili pod kontrolom malih privatnih grupa - često pojedinačnih porodica. No, u devedesetim godinama proteklog veka, tri četvrtine listova našlo se $u$ vlasništvu lanaca.

Danas, trinaest najvećih lanaca kontroliše više od polovine ukupnog tiraža dnevnih listova. Najveći lanac u zemlji je Gannett s više od sto dnevnih i pet stotina drugih listova.

Koncentracijom kontrole nad listovima otežan je pristup pojedincima. U 1900. na svakih trideset šest hiljada ljudi u SAD dolazio je jedan list, dok danas jedan dnevni list dolazi na oko sto sedamdeset hiljada ljudi. Danas je pojedincu mnogo teže da javno iznese svoje mišljenje.

Novija prilagođavanja. Danas je hiljade dnevnih listova prisutno na internetu (videti www.ipl.org), ali dominaciju ima samo mali broj njih. U poslednjih nekoliko godina samo osam od dvadeset najznačajnijih internet sajtova koji se koriste za dobijanje informacija pripojilo se dnevnim listovima.

Više od deset hiljada listova je 2007. imalo veb-sajt i pristup im je bio moguć preko adrese www.onlinenewspapers.com/. Održavanje tih sajtova veoma je jeftino jer dostavljanje već pripremljenih vesti ne zahteva troškove štampe i distribucije. 


\section{DŽEJMS POTER}

\section{Časopisi}

Obim industrije časopisa. Danas postoji 6.248 izdavača časopisa. Oni izdaju više od dvadeset dve hiljade časopisa od kojih su većina (17.000) potrošačkih časopisa od opšteg interesa, ali osam stotina njih ostvaruju tri četvrtine ukupnog prihoda svih časopisa. Svake sedmice na tržištu se pojavljuje deset novih časopisa.

Da bi se svrstao među deset najvećih, jednom časopisu potreban je tiraž od samo četiri miliona primeraka. Časopis s najvećim tiražom (22,7 miliona primeraka) je AARP The Magazine. Manje od devedeset časopisa imaju tiraž od milion ili više primeraka.

Za postojećih deset hiljada časopisa u SAD radi oko dve stotine četrdeset hiljada ljudi.

Prihodi. Industrija časopisa danas ostvaruje godišnji priod od oko 21,5 milijardi dolara.

Značaj prihoda od pretplate veoma se povećao. Prodaja pojedinačnih primeraka časopisa je 1950. činila četrdeset tri odsto prihoda, a pretplata pedeset sedam odsto; danas pretplata čini osamdeset pet odsto prihoda - što ukazuje na nastojanja te industrije da stvara navike kod čitalaca.

Troškovi. Kao i kod dnevnih listova, najveći troškovi časopisa odnose se na zaposlene, ali oni se ne uvećavaju veoma brzo. Za razliku od njih, u poslednjih nekoliko decenija troškovi za papir i poštanski troškovi značajno su se uvećavali.

Konkurencija. Kad je reč o čitaocima i oglašivačima, današnji časopisi nisu u stvarnoj međusobnoj konkurenciji. Na primer, časopis Boy's Life nije u konkurenciji s časopisom Forbes, a Newsweek nije u konkurenciji s časopisom Cosmopolitan. Svaki časopis nastoji da stvori posebnu bazu čitalaca koju može da iznajmljuje svojoj posebnoj grupi oglašivača. Časopisi su orijentisani na ciljne grupe čitalaca i manje su zainteresovani za kvantitet nego za kvalitet čitalačke publike. U okviru ciljnih grupa obično postoji mali broj časopisa koji jesu u međusobnoj konkurenciji. Na primer Newsweek je u konkurenciji s časopisima $T i-$ me i U.S. News \& World Report oko u suštini istih čitalaca i istih oglašivača širom zemlje.

Industrija časopisa podeljena je u specijalizovane grupe. Velike grupe su potrošački (Reader's Digest, TV Guide), informativni (Time, Newsweek) i sportski časopisi (Sports Illustrated, Runner's World), časopisi koji su zastupnici određenih stavova (National Review, New Republic), časopisi za intelektualce (Commentary, American Scholar), časopisi za muškarce 


\section{DŽEJMS POTER}

(Esquire, Gentleman's Quarterly), za žene (Cosmopolitan, Better Homes and Gardens), humoristički (National Lampoon, Mad), erotski (Playboy, Playgirl) i poslovni časopisi (Forbes, Money). Na svakom od tih ciljnih tržišta časopisi su u međusobnoj konkurenciji za čitaoce i oglašivače, ali obično nekolicina časopisa privlači najveći broj čitalaca i najviše novca namenjenog oglašavanju.

Koncentracija. Veliki medijski konglomerati izdaju časopise na više takvih ciljnih tržišta. Na primer, kompanija Time Warner izdaje časopise Time, Sports Illustrated i Money. $\mathrm{U}$ industriji časopisa postoji velika koncentracija. Od svih izdavača časopisa, najveća četiri ostvaruju sedamdeset sedam odsto ukupnih godišnjih prihoda svih časopisa, a najvećih sto šezdeset kompanija ostvaruje osamdeset pet odsto ukupnih prihoda te industrije.

Novija prilagođavanja. Pored štampanih primeraka mnogi časopisi imaju veb-sajtove. Danas postoje i časopisi kao što su Slate (www.slate.com) i Onion (www.theonion.com) koji su dostupni isključivo na internetu.

\section{Film}

Filmskom industrijom se danas smatra filmska i video industrija jer se veliki deo njene proizvodnje odnosi na televiziju, a dobar deo distribucije na video.

Obim filmske industrije. Filmska industrija obuhvata tri posebne oblasti: proizvodnju, distribuciju i prikazivanje. Ima ukupno 16.485 kompanija, i to: 10.595 za proizvodnju, 537 za distribuciju i 5.353 za prikazivanje. Ključna oblast filmske industrije je distribucija i nju kontrolišu holivudski studiji. Oblast prikazivanja čine bioskopi sa ukupno dvadeset šest hiljada filmskih platna.

Prihodi. Prihodi od prodaje ulaznica u zemlji danas iznose oko 9,5 milijardi dolara godišnje, dok se iznajmljivanjem i prodajom video filmova ostvaruju dodatne dvadeset dve milijarde dolara.

Filmski studiji imaju nekoliko osnovnih kanala za ostvarivanje prihoda: iznajmljivanje filmova bioskopima u zemlji, iznajmljivanje filmova $\mathrm{u}$ inostranstvu, prodaja video filmova i davanje filmova u najam televizijskim stanicama. Ove godine bioskopi će prodati ulaznice u vrednosti od oko jedne do 1,3 milijarde dolara u okviru ukupnog prihoda od pet milijardi dolara. Ti prihodi iz godine u godinu rastu ali ne zbog većeg broja posetilaca u bioskopima; rast prihoda rezultat je viših cena ulaznica. Oko sedamdeset odsto prihoda odlazi distributerima filmova. 
Bioskopi ostvaruju prihod od oko 7,8 milijardi dolara kroz svoja dva kanala za priliv prihoda: (a) sopstveni deo od prodaje bioskopskih ulaznica i (b) koncesije s visokom maržom, na primer za prodaju kokica, bezalkoholnih pića i slatkiša, koje čine oko trideset odsto njihovih prihoda. Sjedinjene Države su najveće svetsko filmsko tržište i već više od pedeset godina su najveći svetski izvoznik filmova u druge zemlje. Prihodi od proizvodnje video filmova u zemlji dostigli su u 2004. dvadeset šest milijardi dolara; distribucija u inostranstvu za šest miliona ljudi širom sveta veoma je unosna, ali se gubici zbog piraterije procenjuju na dve milijarde dolara godišnje. Nov i sve značajniji kanal priliva prihoda holivudskih studija jeste ubacivanje pojedinih proizvoda u njihove filmove. Oglašivači danas troše oko tri stotine šezdeset miliona dolara godišnje da bi njihovi proizvodi bili korišćeni u holivudskim filmovima. Još jedan kanal priliva prihoda je sponzorstvo filmskih premijera. Na primer, kompanija za proizvodnju piva Coors sponzor je svih premijera filmova kompanije Miramax Films. Ugovor vredan tri stotine miliona dolara podrazumeva korišćenje proizvoda kompanije Coors u petnaest filmova u toku tri godine, uz stavljanje znaka te kompanije na crvene tepihe na premijerama i služenje njenog piva na prijemima kompanije Miramax. Po prilici, najnoviji kanal priliva prihoda jeste iznajmljivanje filmova preko interneta. Pet velikih holivudskih studija udružili su se u uslužnu kompaniju Movielink koja je u novembru 2002. omogućila potrošačima da u periodu od trideset dana preuzimaju filmove sa interneta i gledaju ih. To je bila direktna konkurencija kompaniji Blockbuster i drugim kompanijama za iznajmljivanje filmova.

Film Titanic zaradio je šest stotina petnaest miliona dolara od prodaje bioskopskih ulaznica u zemlji i 1,2 milijarde dolara od prodaje u drugim zemljama.

Troškovi. Troškovi filmske industrije nikada nisu bili veći nego danas. Krajem 2004. prosečni troškovi proizvodnje jednog holivudskog filma i njegovog plasmana na tržište iznosili su oko sto tri miliona dolara. U 1990. oni su iznosili trideset devet miliona dolara. Najveće povećanje troškova proizvodnje filmova odnosi se na sve veća davanja filmskim zvezdama - čak i onim manje poznatim. Najbolje plaćena zvezda nemog filma 1929. bio je Džon Gilbert koji je zarađivao pet stotina dvadest hiljada dolara godišnje što bi bilo oko osam miliona u 1997. godini. Na vrhuncu slave Klark Gejbl zarađivao je dve stotine osam hiljada dolara godišnje kada je snimao Prohujalo s vihorom i Pobunu na brodu Baunti. Džin Harlou je na vrhuncu karijere zarađivala sedamdeset osam hiljada dolara godišnje. Kao najbolje plaćena glumica tridesetih godina proteklog veka, Garbo je zarađivala dve stotine pedeset hiljada dolara po filmu, a četrdesetih godina najbolje 


\section{DŽEJMS POTER}

plaćena bila je Barbara Stenvik s dve stotine dvadeset pet hiljada dolara po filmu. Današnje filmske megazvezde su Džim Keri, Adam Sendler, Vil Smit i Džulija Roberts koji dobijaju oko dvadeset pet miliona dolara po filmu. Zvezde drugog nivoa zarađuju oko polovine te cifre; na primer, Demi Mur dobija 12,5 miliona dolara po filmu, a Kurt Rasel deset miliona. Glumci trećeg nivoa poput Čarlija Šina dobijaju pet miliona. Nepoznati glumci mogu brzo da uvećaju svoja primanja ako se u svojim prvim filmovima pokažu uspešnim. Na primer, primanja Sandre Bulok povećana su sa šest stotina hiljada dolara za film Brzina na 1,2 miliona za film Dok si spavao, a sada ona dobija više od deset miliona dolara po filmu. I poznati glumci mogu zahvaljujući jednom ili dva uspešna filma da brzo povrate popularnost. Džon Travolta je dobio samo sto pedeset hiljada dolara za film Petparačke priče, a nakon njega je skočio na deset miliona dolara. Čuveni reditelji takođe su veoma dobro plaćeni (obično oko tri miliona dolara), ali ne kao čuveni glumci. Dnevna nadnica za članove američkog Udruženja filmskih glumaca ${ }^{1}$ iznosi pet stotina dvadeset dva dolara što je znatno više od sedmičnog proseka radnika u SAD od pet stotina dolara. No, samo veoma mali procenat od devedeset pet hiljada članova tog Udruženja doista dobije posao. Holivudski studiji troše ukupno oko sto miliona dolara godišnje na testiranje svojih filmova i na propagandne kampanje. Iza odluka o dodeli Oskara ne stoje uvek čisto estetski kriterijumi. Vrši se jaka propaganda za pridobijanje glasača u Filmskoj akademiji; reč je o nadmetanju u popularnosti i bilo je slučajeva da su neki studiji u to uložili čak dvadeset miliona dolara za samo jedan film. Taj novac se smatra ulaganjem. Filmovi koji osvoje nagradu Akademije privlače pažnju publike i raste verovatnoća da će ona odlaziti u bioskope da ih vidi i tako uvećavati prihode studija od tih filmova. Rast troškova proizvodnje filmova navodi studije da postavljaju šefove koji su vičniji poslovanju nego umetnosti. Početkom devedesetih godina minulog veka, šefovi produkcije i filmske zvezde bili su obasipani svim i svačim i sve je činjeno da film bude snimljen. To vreme je prošlo i studiji danas mnogo više vode računa o troškovima.

I nastavci filmova obično su danas skuplji jer filmske zvezde zahtevaju više novca. Na primer, primanja Danijela Radklifa, zvezde filmova o Hariju Poteru, stalno rastu i za film Harry Potter and the Order of the Phoenix koji je snimljen 2006. i čiji su troškovi proizvodnje iznosili tri stotine dvadeset miliona dolara, dostigla su četrnaest miliona dolara.

Rizici. Oblast produkcije je iz više razloga najrizičnija: prvo, od nastanka ideje za jedan holivudski film do početka

1 Screen Actors Guild (SAG) - Prim. prev. 


\section{DŽEJMS POTER}

njegovog prikazivanja u bioskopima prođe oko osamnaest do dvadeset četiri meseca. Kada je reč o televiziji, to traje tri meseca. Otuda postoji rizik da film neće više odgovarati ukusu gledalaca. Drugo, troškovi proizvodnje filma veoma su visoki i neprestano rastu. Prosečni troškovi filmova, uključujući njihov plasman, udvostručili su se u poslednjih pet godina. Prosečni troškovi proizvodnje danas iznose pedeset miliona dolara po filmu plus pedeset miliona za plasman na tržište. To znači da film mora da od prodaje bioskopskih ulaznica ostvari prihod veći od sto miliona dolara da bi počeo da zarađuje novac za studio. Filmovi, međutim, u proseku ostvaruju prihod od oko trideset tri miliona dolara.

Koncentracija. U svim oblastima filmske industrije (proizvodnji, distribuciji i prikazivanju) nivo koncentracije je visok. Iako postoji znatan broj malih nezavisnih producenata, distributera i prikazivača, moć je koncentrisana u rukama nekolicine ogromnih konglomerata koji imaju raznovrsne interese van filmske industrije.

Filmskom industrijom dominira sedam velikih filmskih studija. Na njih dolazi sedamdeset pet odsto celokupne distribucije. Deset najboljih filmova obično svake godine ostvaruju između trećine i polovine ukupnih godišnjih prihoda te industrije. Oko trećine ukupnih prihoda od bioskopskih ulaznica u zemlji ostvaruje se u devet najvećih gradskih oblasti. U sedamnaest letnjih sedmica i u vreme Božića i Uskrsa ostvaruje se četrdeset do pedeset odsto prihoda od ulaznica. Četiri najveće kompanije za prikazivanje filmova ostvaruju oko dvadeset odsto ukupnih prihoda od dvadeset šest hiljada bioskopskih platana u zemlji. Najveći lanac za prikazivanje filmova, Carmike Cinema, ima kontrolu nad 2.401 bioskopskim platnom.

Novija prilagođavanja. U uslovima deregulacije i složenijeg poslovnog okruženja, distributeri se vraćaju prikazivanju filmova. Na primer, kompanija MCA, Inc., koja je vlasnik studija Universal Films, poseduje i četrdeset odsto velikog lanca bioskopa Cineplex Odeon. Kompanija Viacom, u čijem vlasništvu je Paramount Pictures, poseduje i bioskopski lanac Cinamerica. U celini, oko dve hiljade tri stotine bioskopskih platana širom zemlje danas je u delimičnom vlasništvu velikih filmskih studija.

Filmska industrija je uvek nastojala da održava ravnotežu između umetnosti i trgovine, ali odnedavno poslovna orijentacija sve više prevlađuje. Na primer, najnovija postavljenja šefova studija pokazuju da se prednost daje poslovnim ljudima nad onima s kreativnim sposobnostima. Kompanija Warner Brothers imenovala je Barija Majera, pravnika, za predsednika. 


\section{DŽEJMS POTER}

Universal Pictures imenovao je Brajana Maligana, ovlašćenog javnog računovođu, za potpredsednika, a MGM je na visok položaj postavio Krisa Makgerka, bivšeg višeg finansijskog analitičara u kompaniji PepsiCo.

Broj godišnje proizvedenih filmova dramatično je porastao $u$ poslednjih dvadeset godina, od dve stotine osamdeset osam u 1985. na devet stotina u 2005. Proizvodnja jednog filma danas košta u proseku više od sto miliona dolara, a neki koštaju mnogo više. Film Titanik koštao je dve stotine miliona dolara. Kada je reč o prikazivanju filmova, danas postoji više od trideset šest hiljada bioskopa koji u proseku imaju tri stotine četrdeset sedišta. Sedam najvećih kompanija za prikazivanje filmova zajedno kontrolišu više od pedeset odsto bioskopa i osamdeset odsto prodaje bioskopskih ulaznica. Koncesiona prodaja čini dvadeset pet odsto ukupnih bioskopskih prihoda.

\section{Snimanje muzike}

Obim industrije snimanja muzike. U SAD danas postoji više od pet hiljada kompanija za snimanje muzike koje godišnje prodaju 1,2 milijarde traka i diskova.

Takođe postoje hiljade nezavisnih producenata koji pronalaze talente, iznajmljuju studije za snimanje i obezbeđuju proizvodnju kopija snimaka. Potom nastoje da ubede neku od vodećih šest kompanija u toj oblasti da ih distribuira i plasira na tržište. To je posao visokog rizika jer iza samo veoma malog procenta ukupnih muzičkih hitova stoje nezavisni producenti.

\section{Snimljena muzika prodaje se u više od pedeset hiljada prodavnica u zemlji.}

Prihodi. Prihodi od prodaje snimljene muzike iznose oko dvanaest milijardi dolara. Snimak koji se proda u pet stotina hiljada primeraka naziva se zlatnim, ali da bi se smatrao velikim uspehom mora da se proda u deset miliona primeraka; no, to se dešava samo $s$ jednim ili dva snimka godišnje.

Prodavci na malo koji ne uspeju da prodaju sve preuzete trake i diskove vraćaju ih kompaniji za snimanje. Ta kompanija ih potom s velikim popustom nudi članovima klubova. $\mathrm{Na}$ klubove, kao posebnu grupu potrošača, dolazi oko jedanaest odsto ukupne prodaje.

Troškovi. U okviru industrije snimanja muzike troškovi proizvodnje diskova opadaju, dok troškovi angažovanja izvođača rastu. Početkom osamdesetih godina proteklog veka, proizvodnja kompakt diska koštala je tri do četiri dolara, a danas je smanjena na manje od sedamdeset pet centi, uključujući kutiju za čuvanje. 


\section{DŽEJMS POTER}

Glavni troškovi odnose se na umetnike i na oglašavanje. Za ugovor s nekom poznatom grupom danas je potrebno oko pet stotina hiljada dolara. Prodajna cena jednog diska od 16,98 dolara znači da je njegova proizvodnja koštala 7,54 dolara ili, po pojedinim stavkama: 0,65 dolara za snimanje, 1,25 dolara za proizvodnju, 1,30 dolara za pakovanje, dva dolara za oglašavanje, 1,6 dolara za autorska prava izvođača, 0,09 dolara za prevoz, i 0,65 dolara za uplatu u fond za pomoć muzičarima. Proizvođaču nakon toga ostaje profit od 2,94 dolara. Tu su i troškovi i profit distributera u iznosu od 1,5 dolara, dok troškovi i profit prodavaca na malo iznose oko pet dolara. Da bi pokrili troškove, producenti moraju da prodaju najmanje tri do pet stotina hiljada primeraka nekog kompakt diska. Na oko osamdeset odsto svih snimaka novac se gubi.

Koncentracija. Industrija kompakt diskova i traka veoma je koncentrisana, s moćnim distributerima na jednoj i lancima maloprodaje na drugoj strani.

Distribucijom dominiraju četiri velike kompanije: Sony BMG (koja se javlja pod nazivima Columbia, Epic, RCA i Arista), Warner Music Group (Atlantic, Electra i Warner Brothers), Universal Music Group (MCA) i EMI Records (BMI, Capitol i Def Jam Records). Te četiri kompanije kontrolišu devedeset odsto godišnje prodaje snimljene muzike.

U maloprodaji dominiraju veliki lanci. Najveći je Musicland StoresCorp sa više od osam stotina prodavnica.

Oko trećine ukupne snimljene muzike u svetu kupuju Amerikanci. U svetskim okvirima godišnja prodaja dostiže iznos od oko trideset pet milijardi dolara.

Novija prilagođavanja. Kompanije za snimanje muzike i muzičke grupe oslanjaju se na radio-stanice koje će emitovati njihove snimke. Između tih kompanija i radio-stanica nalaze se posrednici koji se nazivaju nezavisnim promoterima snimljene muzike. Tim nezavisnim promoterima koji nastoje da im obezbede emitovanje njihovih snimaka, kompanije za snimanje muzike plaćaju stotine miliona dolara godišnje. Promoteri se povezuju sa određenim radio-stanicama i obećavaju da će im obezbediti reklame. Striktno uzevši, to nije podmićivanje ali nije daleko od toga, mada se ne kosi sa zakonom. Kompanije za snimanje muzike usredsređuju se na hiljadu najvećih od ukupno deset hiljada radio-stanica koje u ovoj zemlji emituju program. To su stanice na najvećim tržištima i imaju najveći broj slušalaca; otuda se kompanije za snimanje muzike oslanjaju na njih u stvaranju hitova i prodaji svojih snimaka. Svake sedmice svaka od tih stanica na svoj spisak za emitovanje stavlja oko tri nova snimka. Nezavisni promoteri bivaju plaćeni 


\section{DŽEJMS POTER}

kada neka stanica emituje snimak kompanije čije proizvode zastupaju. Ukupni prihodi svih takvih promotera iznose oko tri miliona dolara sedmično.

Podmićivanje je protivzakonito ali se ipak primenjuje. Kompanija Sony BMG je 2002. bila uhvaćena da to čini i morala je da plati obeštećenje od deset miliona dolara jer je zaposlenima $\mathrm{u}$ radio-stanicama davala poklone $\mathrm{i}$ novac da emituju njenu muziku.

Perspektivne muzičke grupe nekada su morale da sklapaju ugovor s kompanijom za snimanje muzike da bi mogle da napreduju. Danas grupe stvaraju publiku neposredno na veb-sajtovima. $\mathrm{Na}$ primer, $\mathrm{CD} \mathrm{Baby}^{2}$ predstavlja muziku više od sto pedeset pet hiljada umetnika koji zajedno zarađuju trideset pet miliona dolara godišnje. CD Baby uzima za sebe četiri dolara po prodatom albumu a ostatak predaje umetnicima i na taj način im obezbeđuje znatno veći udeo u prodajnom prihodu od onog koji dobijaju od kompanija za snimanje muzike. Kompanije za snimanje muzike koriste internet kompanije kao bazu za regrutaciju, to jest, ako neka grupa uspe da stvori svoju publiku na internetu, te kompanije znaju da ona ima tržište i nastojaće da s njom sklope ugovor.

Muzička grupa koja sklopi ugovor dobija avans na ime autorskih prava. Ako njen kompakt disk postane zlatan (bude prodat u pet stotina hjiljada ili više primeraka), autorska prava umetnika iznosiće blizu milion dolara. Ali kada ta grupa vrati kompaniji primljeni avans, plati putne troškove, menadžere, pravne zastupnike itd. moguće je da joj neće ostati ništa. Zato muzičke grupe, da bi bile uspešne, moraju da ostvare niz zlatnih diskova i tek tada mogu da sklope povoljnije ugovore koji uključuju veća autorska prava.

Tehnologija snimanja muzike menjala se od plastičnih ploča preko kaseta do kompakt diskova, a sada i do digitalnog preuzimanja muzike koja se reprodukuje na iPodu.

Sedamdesetih godina proteklog veka, snimanje muzike je prešlo sa analognog na digitalno. $\mathrm{Na}$ analognim snimcima zvuk se beležio u obliku talasa te je kretanje igle u brazdama ploče od vinila „čitalo” talase u njima. Kod digitalnih snimaka muzički signali se prebacuju u binarni kompjuterski kôd 0 ili 1 . Digitalni snimci imaju tri velike prednosti. Prvo, zvuk je čistiji. Kod reprodukcije analognih snimaka obično se čulo određeno zujanje koje se digitalnim snimanjem može izbeći. Drugo, kompjuterski binarni kod može se koristiti i za tekstove i video snimke tako da se snimljeni materijal može prebacivati na i sa

$2 C D$ Baby je najveći Internet distributer nezavisne muzike-Prim. prev. 


\section{DŽEJMS POTER}

tih formata bez umanjenja kvaliteta snimka. I treće, binarni kod se može kompresovati radi efikasnijeg prenosa i zauzima manji prostor za skladištenje.

Jedan nemački inženjer je 1987. otkrio način kompresovanja audio fajlova na manje od desetine prvobitne veličine $i$ to je omogućilo lakše slanje fajlova preko postojećih telefonskih veza koje korisnike povezuju sa internetom. Ta tehnologija je nazvana MP3 (MPEG-1 Audio Layer 3).

\section{Radio}

Obim. Broj radio-stanica dramatično se povećao sa oko dve hiljade u 1948. na oko trinaest hiljada pet stotina danas.

U proseku, devedeset četiri odsto Amerikanaca bar jednom nedeljno sluša radio.

Prihodi. Radio danas ostvaruje godišnje prihode od oko dvadeset milijardi dolara, gotovo u potpunosti od oglašavanja. Cena reklamnog spota od trideset sekundi kreće se od hiljadu pet stotina dolara na velikim do nekoliko dolara na malim tržištima. Tri četvrtine tih prihoda ostvaruje se lokalno.

Koncentracija. Isplativost dobro vođenih radio-stanica i ograničen broj stanica, razlozi su što velike kompanije žele da ih kupe. Broj radio-stanica u vlasništvu grupa kompanija stralno raste. U 1929. samo je oko tri odsto od postojećih šest stotina radio-stanica u zemlji bilo u vlasništvu grupa kompanija. Krajem šezdesetih godina minulog veka grupe kompanija posedovale su već oko trećine svih stanica. Zakonom o telekomunikacijama iz 1996. propisi za posedovanje radio-stanica znatno su ublaženi, što je pokrenulo lavinu kupovine te se danas u vlasništvu ogromnih konglomerata nalaze stotine radio-stanica (četiri kompanije poseduju po više od sto radio-stanica svaka, a u vlasništvu kompanije Clear Channel nalazi se više od hiljadu stanica). Samo u 2000. prodato je sto trideset tri AM radiostanica po prosečnoj ceni od oko tri miliona dolara u odnosu na cenu od pet stotina hiljada dolara iz 1995; iste, 2000. godine, sto devedeset dve FM radio-stanice prodate su po prosečnoj ceni od 8,6 miliona dolara, $\mathrm{u}$ odnosu na 2,2 miliona dolara iz 1995. Koncentracija radio industrije raste zahvaljujući nastojanjima Kongresa da izvrši deregulaciju te industrije u pogledu ograničenja broja radio-stanica u vlasništvu jedne kompanije. Kompanija Clear Channel Communications je 2004. posedovala trideset devet televizijskih i hiljadu dve stotine trideset osam radio-stanica.

Radio-stanice se danas obično ne udružuju s nacionalnim mrežama, a i u slučaju takvog udruživanja one od tih mreža preuzi- 


\section{DŽEJMS POTER}

maju samo vesti i posebne emisije. No, to ne znači da današnje radio-stanice imaju raznovrsne programe koji odražavaju potrebe njihovih lokalnih zajednica. One se obično opredeljuju za određene vrste programa kao što su top 40, stari zlatni hitovi, rok albumi, kantri i vestern muzike, sve vrste informativnih i govornih emisija itd. Na primer, na većini radio tržišta postoji jedna radio-stanica koja emituje top 40 i takve stanice zvuče isto širom cele zemlje bez obzira gde se nalaze. Sve one emituju iste pesme, po istoj rotaciji, imaju iste najavne i odjavne špice, donose istu vrstu vesti predstavljenih na isti način i imaju iste vrste kvizova i oglasa.

Novija prilagođavanja. Pored emitera redovnih radio programa, od 2002, kada su se na tržištu našle i satelitske radio-stanice SM i Sirius, postoje i satelitski radio programi. To su radio-stanice bez oglasa koje slušaocima nude više različitih programa. Pretplatnici na satelitske radio programe kupuju poseban prijemnik i

potom plaćaju mesečnu pretplatu za prijem signala.

\section{Emiteri klasičnih TV programa}

Obim. Emitera redovnih TV programa ima 1.937.

Prihodi. Emiteri redovnih TV programa ostvaruju ukupne godišnje prihode od oglašavanja od oko četrdeset dve milijarde dolara. Televizijski reklamni spot od trideset sekundi košta u proseku sto hiljada dolara, a za emisije najvišeg rejtinga i u udarnom vremenu cena dostiže i pet stotina hiljada dolara.

Ubacivanje proizvoda u sadržaj emisija još je jedna vrsta oglašavanja čija je prednost što se dešava u toku emisija a ne za vreme prekida.

Troškovi. TV emisije postaju sve skuplje, dok broj gledalaca opada. U jesen 2006. troškovi jednočasovne jednosezonske dramske serije porasli su na šezdeset dva miliona dolara - u odnosu na četrdeset pet miliona u 2004. Jedan od razloga tog povećanja je visoka cena zvezda tih serija koje dobijaju više od sto hiljada dolara po epizodi. I oglašivači počinju da izbegavaju visoke i stalno rastuće cene oglašavanja u emisijama u udarnim TV terminima i svoj novac sve više prebacuju na internet.

Troškovi kreativnog dela proizvodnje TV emisija čine šezdeset odsto budžeta televizijskog programa.

Rizici. Stvaranje TV emisija nosi sa sobom veliki rizik. Nacionalne TV mreže godišnje pregledaju oko četiri hiljade predloga za nove televizijske serije; samo za oko sto njih se snima probna verzija, a od tih sto samo oko dvadeset pet biva emitovano: od njih pak samo će dvanaestak trajati celu sezonu. 


\section{DŽEJMS POTER}

Nezavisni producenti stvaraju emisije i potom ih iznajmljuju TV mrežama - ali uz gubitak. Proizvodnja uobičajene epizode polučasovnog sitkoma košta oko osam stotina hiljada dolara, a producent dobija samo oko šest stotina hiljada dolara po epizodi za dva prikazivanja (premijerno i reprizno), te gubi dve stotine hiljada dolara po epizodi. Posle dve godine proizvodnje (četrdeset četiri epizode) producent ima dug od oko osam miliona dolara. Dug producenata jednočasovnih dramskih serija iznosi oko četrnaest miliona dolara. Te dugove pokrivaju filmski studiji koji kao deo dogovora o paketu usluga obezbeđuju i proizvodnju. Ako je serija uspešna i bude ponavljana, producenti i filmski studiji uspevaju da povrate uloženi novac pa i da zarade. Kada su 1988. počela ponovna prikazivanja TV serije Cosby Show, producenti su zaradili više od osam stotina miliona dolara, a pošto su epizode već bile snimljene to je bio gotovo čist profit. Proizvodnja informativnih emisija i rieliti šoua mnogo je jeftinija, ali oni ne privlače toliku pažnju prodavaca emisija TV mrežama.

Troškovi i rizici čine da je nezavisnih televizijskih producentskih studija sve manje. Od jeseni 2003. samo je jedan - CarseyWerner-Mandabach - napunio svoj sef zahvaljujući uspešnim serijama The Cosby Show i Roseanne. Do 1995, emiteri TV programa nisu mogli da budu vlasnici sopstvenih emisija; morali su da od producenata kupuju prava za prikazivanje. Od 1995, stvaraju i proizvode sopstvene emisije. Proizvodnja polučasovnog sitkoma obično košta milion dolara po epizodi, a jednočasovna dramska emisija 2,2 miliona dolara. U jesen 2003, sedamdeset sedam odsto svih emisija u udarnom terminu bilo je u vlasništvu šest velikih televizijskih mreža.

Koncentracija. Oglašavanje na komercijalnoj televiziji koncentrisano je u rukama nekolicine veoma velikih oglašivača koji mogu da kupuju velike količine vremena za oglašavanje godišnje. Na primer, na dvadeset kompanija dolazi više od polovine ukupnog oglašavanja na televizijama koje emituju redovni program.

Novija prilagođavanja. Udeo emitera redovnog televizijskog programa, kada je reč o publici, opao je sa devedeset dva odsto u 1978. na četrdeset sedam odsto u 2002, i nastavlja da opada. Masovna publika ne sedi više ispred televizora radi redovnog gledanja TV programa. Danas sve veći broj ljudi televiziju gleda preko dana zahvaljujući video snimcima sa prenosivih uređaja kao što su iPodi i mobilni telefoni, kao i kancelarijski kompjuteri i laptopovi. To utiče i na stvaranje programa jer se publika sada deli i po vremenu gledanja televizije. TV mreže će morati da prelaze na jeftinije emisije kao što su rieliti šou i kvizovi jer 


\section{DŽEJMS POTER}

niko ne može sebi da dozvoli luksuz tročasovnog prikazivanja skupih emisija svake večeri.

Televizijske stanice su 1998. počele sa emitovanjem HDTV ${ }^{3}$ i danas gotovo sve lokalne stanice emitiju HDTV program.

\section{Kablovska televizija}

Kablovska televizija se danas smatra delom industrije kablovske i satelitske televizije i time se razlikuje od emitera redovnih televizijskih programa.

Obim. Danas postoji devet hiljada pet stotina dvadeset pojedinačnih kablovskih sistema koji opslužuju šezdeset osam odsto svih domaćinstava koja poseduju televizor.

Postoji tri stotine trideset devet mreža kablovske televizije, kao što su ESPN, BET, Bravo, MTV, ScFi, TBS, USA Network i Family Channel.

U ovoj industriji je u oblastima proizvodnje, distribucije i prikazivanja zaposlena sto trideset jedna hiljada ljudi.

Prihodi. Ukupni godišnji prihodi danas iznose oko šezdeset milijardi dolara. Kablovska televizija ima dva osnovna kanala priliva prihoda: pretplatu i oglašavanje. Najveći deo prihoda kablovska televizija ostvaruje od pretplate. No, ona danas veoma uspešno konkuriše emiterima redovnih TV programa u pogledu prihoda od oglašavanja. Ti prihodi kablovske televizije uvećani su sa pedeset osam miliona dolara u 1980. na 11,2 milijarde dolara u 1999.

Troškovi. U periodu 1998-2003, troškovi kablovske televizije uvećani su za četrdeset odsto. Tako veliko povećanje posledica je rastućih troškova produkcije programa i ulaganja u novu tehnologiju.

Kablovski operateri moraju da kupuju emisije koje prikazuju. Ti troškovi kreću se od oko pet centi po pretplatniku mesečno za kanale niske tražnje, kao što je C-Span, do oko 2,6 dolara za kanale visoke tražnje, kao što je ESPN.

Koncentracija. Nema ograničenja u pogledu vlasništva kada je reč o veličini operatera višestrukih sistema. ${ }^{4}$ Tokom proteklih trideset godina, najveći takvi operateri nastavili su da učvršćuju svoje pozicije i da stvaraju efikasne grupe. Pet najvećih kontrolišu sedamdeset tri odsto svih američkih domaćinstava $\mathrm{s}$ kablovskom televizijom, $\mathrm{u}$ odnosu na trideset osam odsto u 1993.

3 High-definition television-Televizija visoke rezolucije-Prim. prev.

4 Multiple systems operator (MSO) - Prim. prev. 


\section{DŽEJMS POTER}

U 2000, prodata su dvadeset dva sistema kablovske televizije po prosečnoj ceni od pedeset pet miliona dolara, što iznosi šest hiljada dve stotine pedeset devet dolara po pretplatniku.

Novija prilagođavanja. Najveći konkurent kablovskoj televiziji je DBS (Direct Broadcast Satelite) ${ }^{5}$ koji danas obuhvata oko četvrtine tržišta višekanalske video distribucije, dok kablovska televizija obuhvata preostale tri četvrtine.

\section{Kompjuteri: internet}

Očigledno je da je kompjuterski medij daleko odmakao u fazi prodora. Da li će kompjuteri dospeti do faze vrhunca i zameniti kablovsku televiziju u ulozi dominantnog medija ostaje da se vidi.

Obim. Globalna kompjuterska mreža ${ }^{6}$ narasla je na oko osam stotina miliona strana. To je veoma značajan resurs, ali postoji problem pristupa njegovim delovima. Najsveobuhvatniji pretraživač danas obuhvata samo šesnaest odsto te mreže; nivo pristupa većine pretraživača manji je od deset odsto. Čak i ako bismo koristili sve pretraživače bilo bi nam dostupno samo četrdeset dva odsto te mreže jer je toliki obim njene trenutne indeksiranosti.

U 2000. u svetu je bilo više od pet stotina miliona korisnika interneta.

Prihodi. Internet je u 2000. ostvario prihode u vrednosti od trinaest milijardi dolara, od čega se dve trećine odnosi na korisnike a jedna na oglašivače.

Troškovi. Da bi ovaj novi medij bio finansijski uspešan moralo se utrošiti mnogo novca za izgradnju infrastrukture. Za prenos informacija u američka domaćinstva bili su potrebni kablovi od optičkih vlakana. Ti kablovi mogu da prenose ogromnu količinu informacija. Starim telefonskim linijama moguće je prenositi nekoliko stranica teksta u sekundi, dok samo jedna linija od optičkih vlakana debljine vlasi kose može da prenese oko pet hiljada strana u sekundi. Lokalne telefonske kompanije utrošile su oko sto milijardi dolara za izgradnju mreža koje sve domove i zgrade povezuju kablovima od optičkih vlakana - očekuje se da taj posao bude završen do 2010. Troškovi osoblja su relativno visoki i stalno rastu. Na primer, prosečna godišnja primanja 1,4 miliona ljudi zaposlenih na pružanju softverskih usluga iznosila su 1997. pedeset osam hiljada šest stotina osamdeset osam dolara; prosečna primanja 1,6 miliona

5 Satelit za neposredno emitovanje programa-Prim. prev.

6 World Wide Web (WWW) - Prim. prev. 


\section{DŽEJMS POTER}

ljudi zaposlenih na projektovanju hardvera, u proizvodnji i održavanju bila su pedeset tri hiljade četrdeset četiri dolara. Te iznose treba uporediti s prosečnim godišnjim primanjima Amerikanaca u svim industrijama od dvadeset dve hiljade devet stotina osamdeset četiri dolara.

Koncentracija. Kompjuterska industrija je izrazito nova te kompanije brzo rastu, bivaju kupljene od strane velikih kompanija ili nestaju s tržišta. No, postoje trendovi koji ukazuju na prisustvo koncentracije. U ovom novom mediju već postoje znaci koncentracije. Na primer, osamdeset odsto svih oglasa koji se iznenada pojavljuju odnosi se na samo šezdeset tri kompanije.

Novija prilagođavanja. Još 1980. domaćinstva su bila povezivana bakarnim žicama koje su mogle da prenose manje od jedne strane informacija u sekundi. Već 2006. najveći deo zemlje bio je povezan optičkim kablovima koji posredstvom staklenih vlakana debljine vlasi kose mogu da prenose informacije obima od više od devedeset hiljada enciklopedijskih tomova.

Stopa rasta elektronske trgovine je dramatična. U 1997, ta trgovina je u okviru maloprodaje na internetu ostvarila samo oko dve milijarde dolara; u 2002, taj iznos je dostigao skoro sto milijardi dolara, a očekuje se da će u 2007. dostići dve stotine pedeset devet milijardi i da će se više od deset odsto ukupne prodaje odeće obavljati posredstvom interneta.

Kompjuteri i digitalizacija doprinose međusobnom približavanju medija. Nove tehnologije, naročito digitalizacija, čine da se kompanije sve više određuju na osnovu svojih produkata a ne kanala distribucije. Na primer, televizijske mreže se mnogo manje određuju kao televizija, a više kao izvori zabave i informacija.

Kvizovi se pojavljuju i na internetu. Zlatna groznica je igra u kojoj takmičari odgovaraju na jednostavna pitanja o AOL. ${ }^{7}$ Finalisti te igre bivaju pozvani u jedan grad i takmiče se pred veb kamerama za nagradu od sto hiljada dolara. Producent te igre, Maks Bernet, koji je takođe producent igara Survivor i Apprentice, nazvao ju je ,interaktivnom rieliti igrom”. Ta igra donosi mnogo novca tako što u sebe uvršćuje proizvode postavljanjem pitanja o njima. Proizvodni troškovi za tu igru iznose deset miliona dolara a ona donosi prihode od dvadeset pet miliona dolara od oglašavanja.

Prihodi od pretplate na AOL svake godine su sve manji, ali prihodi od oglašavanja rastu - u periodu 2004 -2006. više su se nego udvostručili i dostigli su skoro četiri stotine pedeset

7 America Online - Američka globalna Internet mreža - Prim. prev. 


\section{DŽEJMS POTER}

miliona dolara (Roberts, 2006c). AOL je pretrpeo izmene i od prvenstveno provajdera internet usluga pretplatnicima postao je besplatni veb-sajt koji nastoji da privuče što je moguće više posetilaca kako bi uvećao svoje prihode od oglašavanja. Da bi ostvario navedeni cilj on nudi vesti, zabavu i druge usluge. U martu 2007. imao je 94,9 miliona posetilaca što ga čini jednim od najposećenijih veb-sajtova, uz Google (sto osam miliona posetilaca mesečno), Yahoo (sto sedam miliona), MSN

(95,3 miliona) i Fox/MySpace (65,1 miliona).

Veliki mediji su iznenađeni naglom popularnošću kratkih bitova na veb-sajtovima kao što su YouTube.com i MySpace. com i na milionima sićušnih ekrana od iPodova kompanije Apple do nove generacije mobilnih telefona. YouTube nudi više od sto miliona snimaka dnevno i svakog dana unosi šezdeset pet hiljada novih.

\section{Plate}

U celini gledano, prosečne plate najviše su u softver kompanijama i rastu brže u njima nego u bilo kojoj industriji masovnih medija. Do njih se došlo podelom iznosa ukupnih plata $\mathrm{u}$ jednoj industriji s brojem plaćenih radnika u njoj. U nekim medijskim industrijama, kao što je filmska, ima veoma mnogo ljudi koji rade za minimalne plate, dok mali broj njih zarađuje desetine miliona dolara godišnje. Iako proseci mogu da navode na pogrešne zaključke, oni ipak mogu biti korisni kao relativan pokazatelj primanja zaposlenih $\mathrm{u}$ raznim medijskim industrijama ako se koriste za procenu početne plate u nekoj od njih.

Zanimljivo je pogledati i primanja u okviru pojedinih industrija. $\mathrm{Na}$ primer, u filmskoj industriji, razlike u primanjima veoma su velike. Najveća primanja donose poslovi koji najviše doprinose privlačenju brojne publike.

\section{Demografija}

Pogled na ukupnu situaciju radne snage u ovoj zemlji otkriva tendenciju rasta broja žena koje su zaposlene van svojih domova. Žene danas čine četrdeset pet odsto radne snage. Razvojem medijskih industrija došlo je do povećanja zaposlenosti žena, ali u masovnim medijima i dalje radi mnogo veći broj muškaraca.

Medijske industrije s najvišim procentom zaposlenosti žena su industrije časopisa i knjiga i u njima žene čine više od pedeset odsto radne snage. Najveći rast procenta zaposlenosti žena zabeležen je u časopisima. U 1960, samo dvadeset odsto zaposlenih u časopisima bile su žene, ali se taj procenat svake godine 


\section{DŽEJMS POTER}

povećavao. Glavni uzrok tog povećanja bio je prelaz štampanih medija s tradicionalno muških štamparskih poslova na pretežno kancelarijske poslove i na rad koji je orijentisan na tehnologiju. Kod emitera programa, žene su u 1960. činile dvadeset tri odsto zaposlenih. Taj procenat nije se značajnije menjao sve do 1972. kada je federalna vlada počela da prati način zapošljavanja u kompanijama. Otada dolazi do postepenog povećanja tog procenta na oko trideset odsto.

U filmskoj industriji, žene čine oko četrdeset odsto zaposlenih, ali taj procenat je u pojedinim oblastima te industrije različit. U velikom sektoru prikazivanja (kontrolori ulaznica, koncesioni radnici, filmski operateri itd.) oko četrdeset pet odsto zaposlenih su žene. No, u oblasti produkcije (glumci, reditelji, producenti i scenaristi) devedeset pet odsto zaposlenih su muškarci.

\section{Novinarstvo}

Novinarstvo je popularna profesija u medijskim industrijama. Njime se bavi oko šezdeset sedam hiljada izveštača i dopisnika, dvadeset tri hiljade pisaca tekstova i urednika i šezdeset sedam hiljada radio i televizijskih najavljivača i voditelja emisija vesti. Većina njih su muškarci, belci i mladi. Oko trećine zaposlenih novinara su žene, što je iznenađujuće nizak procenat kada se ima u vidu da je oko dve trećine polaznika novinarskih škola u protekloj deceniji bilo ženskog roda. Samo oko osam odsto su pripadnici etničkih manjina (3,7 odsto su Afroamerikanci, 2,2 odsto Hispanci, jedan odsto azijski Amerikanci i 0,6 odsto američki domoroci). Više od polovine američkih novinara mlađi su od trideset pet godina, a samo deset odsto ih ima pedeset pet ili više godina. Gotovo svi poseduju diplomu koledža, bilo iz žurnalistike ili njoj sličnih oblasti kao što su englesko ili američko društvo i političke nauke. U SAD postoji više od tri stotine univerziteta čiji nastavni programi uključuju novinarstvo/masovne komunikacije i svake godine diplomu iz tih oblasti stiče oko dvadeset hiljada studenata.

\section{Pisci tekstova}

$\mathrm{Na}$ televiziji i u filmskoj industriji većina pisaca tekstova su muškarci i većina njih su mladi. Firma Bilbi i Bilbi (2001) sakupila je podatke o karijerama osam hiljada devet stotina devedeset televizijskih i filmskih pisaca i ustanovila da su oni u proseku sve mlađi. Istraživači su tu tendenciju objasnili time što marketinške strategije na televiziji i filmu bivaju sve usmerenije na mlađu publiku; te industrije angažuju mlađe pisce čiji tekstovi privlače tu ciljnu grupu. Udruženje američkih pisaca okuplja oko tri hiljade zaposlenih TV pisaca, a među njima samo deset od- 


\section{DŽEJMS POTER}

sto su pripadnici etničkih manjina, dok su dvadeset sedam odsto žene. Situacija u filmskoj industriji još je lošija. Od hiljadu sedam stotina sedamdeset filmskih pisaca šest odsto su pripadnici etničkih manjina a osamnaest odsto su žene.

\section{Oglašavanje}

Prema podacima Američkog udruženja oglasnih agencija, one zapošljavaju oko sto hiljada ljudi: oko dvadeset četiri odsto na kreativnim poslovima, petnaest odsto na poslovima s klijentima, deset odsto na saradnji s medijima, deset odsto na finansijskim poslovima, osam odsto na posebnim uslugama, a ostatak na sekretarskim i adimistrativnim poslovima (to jest, oko trideset tri odsto). Broj zaposlenih u reklamnim agencijama raste za oko tri odsto godišnje. Žene čine trideset četiri odsto zaposlenih u ovoj oblasti a samo sedamnaest odsto njih su na rukovodećim radnim mestima. Razlika u primanjima između muškaraca i žena se smanjuje. Analiza primanja objavljena u časopisu Advertising Age u 2003., pokazuje da na radnim mestima iste vrste i dalje postoje razlike u primanjima muškaraca i žena; no, te razlike uglavnom su svedene na manje od deset odsto, a za neka radna mesta (poput kreativnog direktora i menadžera koji radi sa klijentima) primanja su gotovo ista.

\section{Status}

Žene zaposlene u medijskim industrijama obično se nalaze na nižim položajima, zarađuju manje novca i imaju niži nivo obrazovanja. Na primer, u dnevnoj štampi žene zauzimaju oko sto dvadeset rukovodećih uredničkih položaja u hiljadu sedam stotina dnevnih listova u SAD. Kada je reč o položajima na kojima se odlučuje o politici poslovanja žene drže tri stotine šezdeset jedno takvo radno mesto (jedanaest odsto), dok ih muškarci drže tri hiljade pedeset sedam (osamdeset devet odsto). U izdavačkoj delatnosti oko šezdeset četiri odsto urednika, potpredsednika i stručnjaka su muškarci; no, u manjim izdavačkim kućama zastupljenost žena je veća.

\section{Zaključak}

U medijskim industrijama radi manje ljudi nego što se to obično misli. Njihova demografija ne podudara se s demografijom ukupnog stanovništva ove zemlje. Iako mediji nastoje da zapošljavaju veći broj žena i pripadnika etničkih manjina, njihovo prisustvo u radnoj snazi medija i dalje je veoma malo.

Preveo s engleskog

Đorđe Trajković 